\title{
A Proposed Sustainable Transportation and Urban Mobility Design
}

\author{
Behnam Neyestani \\ Department of Civil Engineering, De La Salle University, Manila, Philippines \\ (E-mail: behnam_neyestany@dlsu.edu.ph).
}

\begin{abstract}
The Urban Mobility Design is city's comprehensive resource on street design guidelines, policies, and processes. It aggregates a broad range of resources from nationally recognized engineering and design guidelines. It supplements rather than replaces existing engineering and environmental standards, requirements, or guidelines, such as the Manual on Traffic Control Devices and Policy on Geometric Design of Highways and Streets. In a city with as many varied and complex conditions as Metro Manila, designs should be tailored to the particular needs and opportunities created by the local context, uses, and dimensions of streets. The purpose of this study is to find the problems of transportation and mobility, and likewise propose the appropriate solutions based on principles of sustainability in city's transportation.
\end{abstract}

\section{Urban Transportation design}

\subsection{Street Design Policy of Urban Transportation design}

Planning and designing streets in accordance with the goals and principles of this section will contribute to a consistent level of quality and functionality for Manila City's streets. This policy, along with the project's planning framework, should be used to resolve conflicting priorities for limited street space.

\subsection{Goals \& Principles of Urban Transportation design}

\subsubsection{Design for Safety}

The city's efforts to enhance street safety through engineering, education, and enforcement have contributed to a dramatic drop in the number of pedestrian fatalities and serious injuries in Manila. Designing safe streets will continue to be the first priority. For getting this aim (safety), Urban Transportation design should be considered three points [4], [3], [7] such as:

I. Prioritize safety for all street users, particularly more vulnerable groups (children, the elderly, those with disabilities) and more vulnerable modes (walking, bicycling);

II. Design local streets for slower speeds to reduce the number of crashes and to discourage cut-through traffic, and;

III. Research, test, and evaluate innovative safety treatments, particularly those successfully adopted in other cities.

\subsubsection{Design to Balance access and Mobility}

Urban Transportation designs should provide efficient ways to move people and goods and improve the economic vitality of the city, but not at the expense of safety and 
community needs; street designs should therefore balance access within neighborhoods with mobility through them [5], [8]. For getting this aim, Urban Transportation design should be considered four points such as:

I. Provide safe, accessible, convenient, and comfortable facilities for walking, bicycling, and transit, particularly on designated routes and at critical network connections;

II. Accommodate truck traffic, and deliveries while minimizing their negative impacts on neighborhoods;

III. Meet or exceed americans with Disabilities Act (ADA) standards, and;

IV. Accommodate emergency vehicle access.

\subsubsection{Design for Context}

Streets help define the character of neighborhoods. Except for standard furniture, materials, and lighting, a street's design should interact with the surrounding context, including its history, land uses, and nearby landmarks. For getting this aim, Urban Transportation design should be considered three points [2], [4], [8], such as:

I. Preserve the unique character of neighborhoods;

II. Support connections to adjacent land uses by providing gathering spaces and pedestrian access to and from major destinations, and;

III. Maintain aesthetic consistency within neighborhoods and corridors.

\subsubsection{Design Streets as Public Spaces}

Beyond their use for moving people and goods, streets comprise an extensive network of public open spaces that can facilitate social, civic, and economic interactions [1]. For getting this aim, Urban Transportation design should be considered four points such as:

I. Expand usable public open space by reallocating underutilized roadway space for pedestrian plazas, expanded sidewalks, corner and mid-block curb extensions, and opportunities for greenplanted areas;

II. Design streets to encourage physical activity for all ages and populations by making walking, bicycling, and transit attractive and convenient;

III. Design local streets to be trafficcalmed environments that encourage walking, bicycling, and recreational activities, and;

IV. Expand the availability of public seating and bicycle racks.

\subsubsection{Design for Sustainability}

Streets present an extraordinary opportunity to improve the environmental health of the city [10]. Collaborate across agencies in testing, evaluating, and standardizing new materials so that streets are constructed in an environmentally sound way [3]. For getting this aim, Urban Transportation design should be considered three points such as:

I. Minimize impermeable surfaces and maximize vegetation on streets. Street designs should use stormwater source controls wherever possible;

II. Reduce streets' rate of heat absorption by maximizing tree canopy cover, and;

III. Minimize the overall lifecycle energy use and pollution associated with projects, including the extraction, transportation, construction, and replacement of materials. 


\subsubsection{Design for Cost-Effectiveness}

Reconstruction of city streets requires substantial financial resources. The list of worthy projects competing for a limited pool of funding is extensive. Street designs need to be cost-effective [4], [2]. For getting this aim, Urban Transportation design should be considered four points, [6], [7], [1], such as:

I. Consider not only up-front capital costs, but also full lifecycle costs and benefits; certain options may cost more up front, but may have lower ongoing maintenance and operations costs and/or provide long-term benefits;

II. Design streets to meet the city's future needs. Because streets are reconstructed infrequently, consideration of future conditions and needs should be part of the planning process;

III. Maintain a clear and consistent design-review process to streamline project review, and;

IV. Establish well-considered and clearly defined goals early in project development and focus on meeting those goals throughout planning and design.

\section{Scope of Analysis and Levels of Planning}

This case study is limited from Taft Ave. to Mabini St. and another side from Vito Cruz St. (Menlo and Balagtas) to Quirino Ave., as shown in Figure 1 and 2, that focused on the evaluation of the problems and challenges of transportation issues in that area in Metro Manila, Philippines. It is important to recognize that the nature of problems to be examined dictates the level of planning to be used as well as the technique for travel demand analysis. The time frame of this analysis was 2014 inclusive.

There are different levels of planning directed to different types of problems. The terminology for these levels of planning and analysis varies according to the context [6]. Even for a particular level of analysis, the techniques may have to be adjusted to match the constraints of available data. In this case traffic engineers would be interested in detailed traffic flow characteristics including turning movements of vehicles along each approach, and pedestrian volumes across each approach [5]. Management strategies in this case would involve traffic operation and roadway design oriented techniques.

This analysis is primarily identification and determination of the problems and challenges of transportation issues and finding good methods and techniques to solve them through sustainable transportation design in selected area (Figure 1) in Metro Manila, Philippines. Since the study focuses on the introduction of the problems and challenges of transportation, the researcher observed and took pictures of that zone as his method in gathering necessary information about the problems and challenges of transportation. 


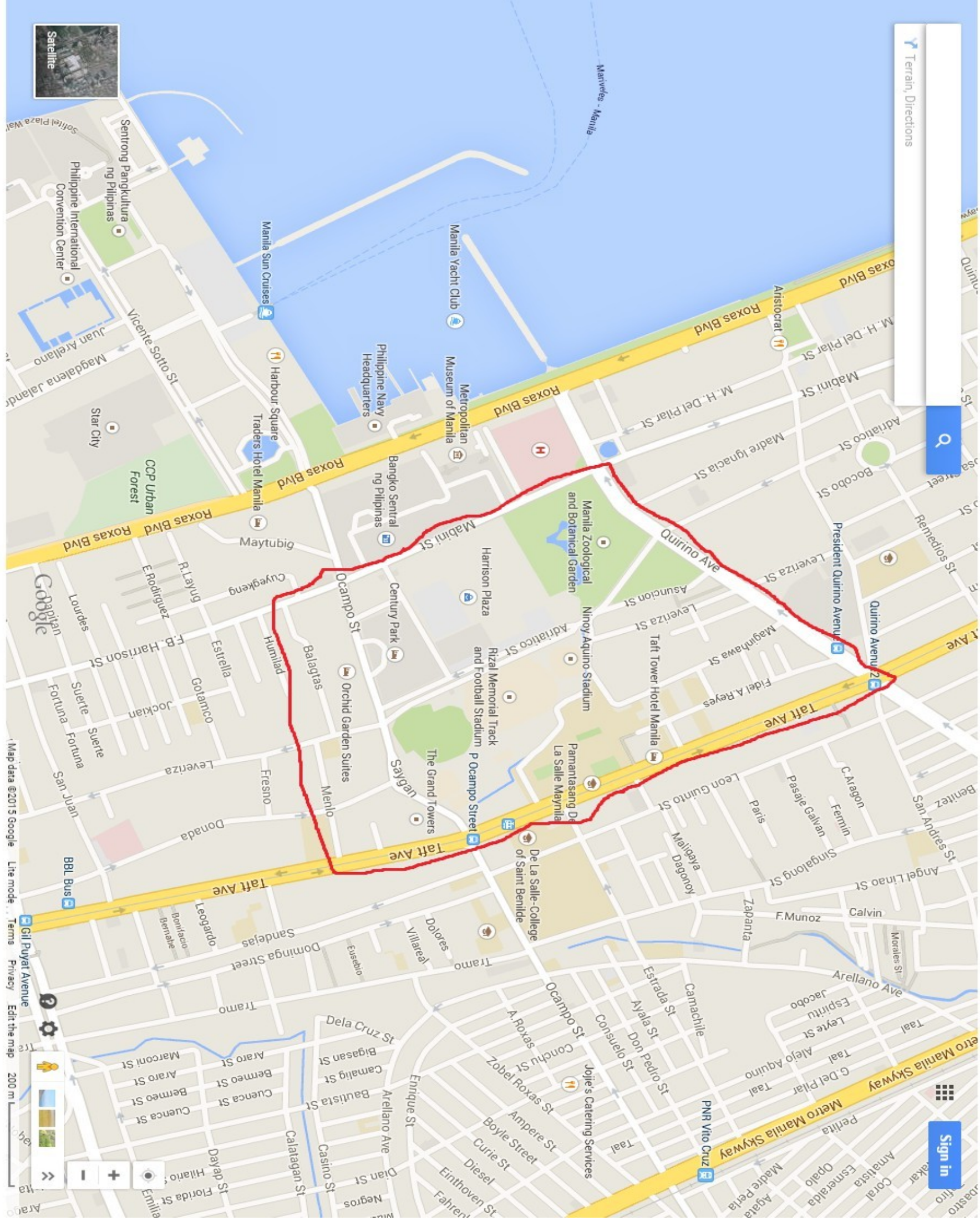

Figure 1. Study Scope 


\section{Sustainable Urban Mobility Plan}

With rapid urbanization and economic growth, motorization has been accelerating in cities in developing countries like Manila, Philippines. Owning a private car or a motorized two-wheeler is a major aspiration for people in this city, in particular, where non-motorized transport and public transport service is often inadequate and unsafe [2].

Nowadays, many cities in developed countries are now trying to recover from the cardominated development to public transport and non-motorized transport. This approach has been called in some cases a "road diet" or "complete streets" (the first is one where space for cars is explicitly reduced, the second emphasizes the need for streets where all road users are catered to). Sustainable Urban Mobility Plan is essentially a transport masterplan looking at the way people move around by different modes of transport. These include walking, cycling, bus, train, taxi, motorcycle, car, van and Heavy Goods Vehicle (HGV). To develop the most effective Sustainable Urban Mobility Plan, is essential that the public and stakeholders are involved in its development to ensure that the end result is something which brings them the greatest benefit [8]. The following principles are required for a successful SUMP:

- Ensuring the transport system is accessible to all;

- Improving the safety and security of its users;

- Reducing air and noise pollution, greenhouse gas emissions and energy consumption;

- Improving the efficiency and cost-effectiveness of the transportation of people, and;

- Enhancing the attractiveness and quality of the urban environment.

Public transport and non-motorized transport essentially reduces the problem of congestion to a lack of sufficient road space and a need for better traffic flow. Policies for more and more road construction have clearly failed to cope with ever increasing demand from rapid motorization, resulting in a vicious circle as depicted [3] in Figure 2. This cycle shows how the increase of infrastructure to alleviate travel demand will have apparently positive consequences in the short term, but some months later there will be a much greater congestion than before, thus increasing the problem rather than solving it.

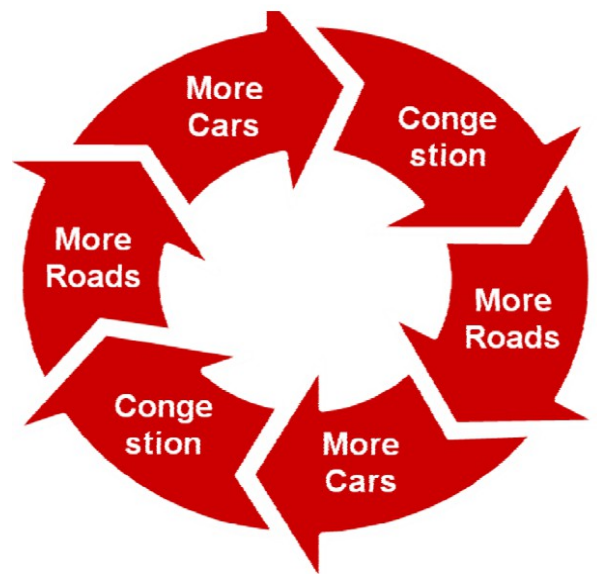

Figure 2. Vicious Circle of Car-Oriented Transport Development [3]

Non-Motorized Transport as walking and cycling (and all other modes that have wheels but no engine such as pedicabs and freight tricycles), as well as related infrastructure, policies and education. These modes have been greatly promoted recently due to their great 
benefits for reducing transport emissions and for improved human health [10]. While encouraging a shift to non-motorized transport modes, however, the report acknowledges that such modes are best suited for local travel and that motorized transport (in particular public transport) has an important role while travelling longer distances [9]. However, in many (if not most) countries there is a considerable stigma against public transport. The privatecar is often seen as the most desirable travel option. There is thus a need to enhance the acceptability of public transport systems. More needs to be done to increase reliability and efficiency of public transport services and to make these services more secure and safe. Also, bicycle can be a good solution for problems of traffic and pollution side by side public transport, the purpose of bicycle lanes is to clearly divide the path of bicyclists from the path of motorists on a mixed roadway in a way that is easily recognizable to both. As opposed to separated cycle tracks, bicycle lanes force bicyclists and motorists to share the same road and thus must be carefully designed to be safe and enjoyable for cyclists [7].

\section{Analysis of the Problems and Challenges of Urban Mobility in Selected Area in Metro Manila}

In order to develop guidelines for traffic planning and design, it is very necessary to employ proper methods and processes to analyze towards desiging suitainable transportation. In its last step of this case, the results will be sammarized and categorized in SWOT analysis form the base for an alternative suitainable transportation design proposal. Finally, guidelines shall be drived from design proposal demonstrating [6]. The process of suitainable transportation design proposal can be, as shown in Figure 3.

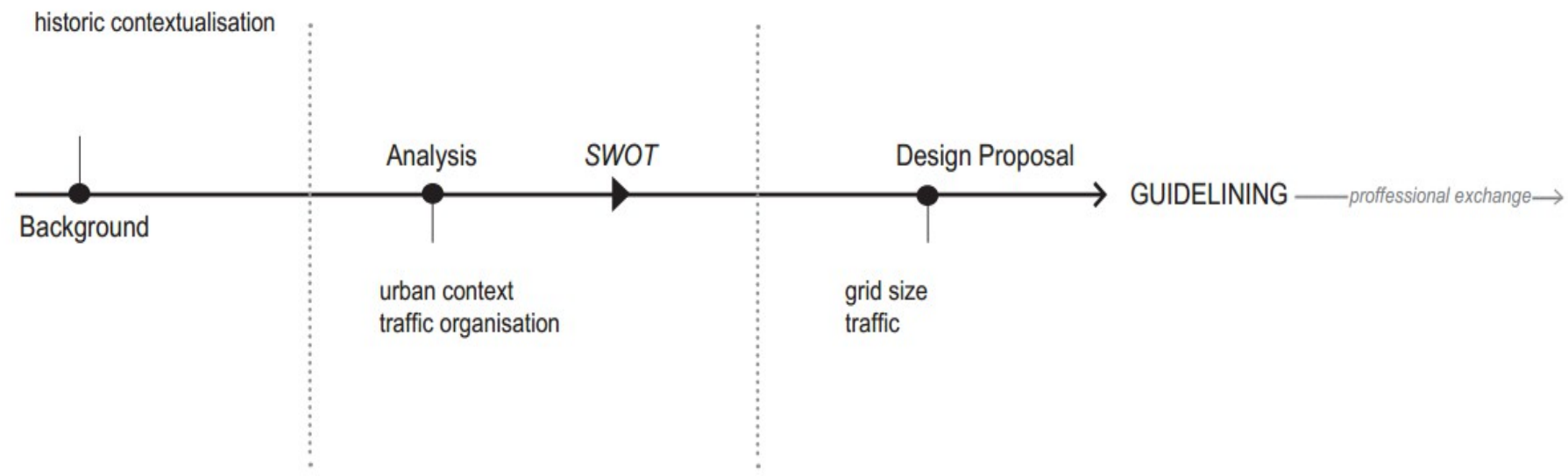

Figure 3. The Process of Suitainable Transportation Design Proposal

The best method to desing sustainable urban transportation is to observe and finding transportation problems in selected area [5], [6]. After determining the problems which are existed in the roads, sidewalk, traffic jam and etc., it can be easy to find an efficient solution for those problem by using principles and regulations of sustainable transportation. The observation and photography can help to analyze and find the problems of the transprtation in selected area in Metro Manila. So, there are two main steps for collecting data and understanding well concerning problems of urban mobility before designing that the steps are:

1. Observation, and Photography, and;

2. Analysis of Photography. 


\subsection{Observation \& Photography}

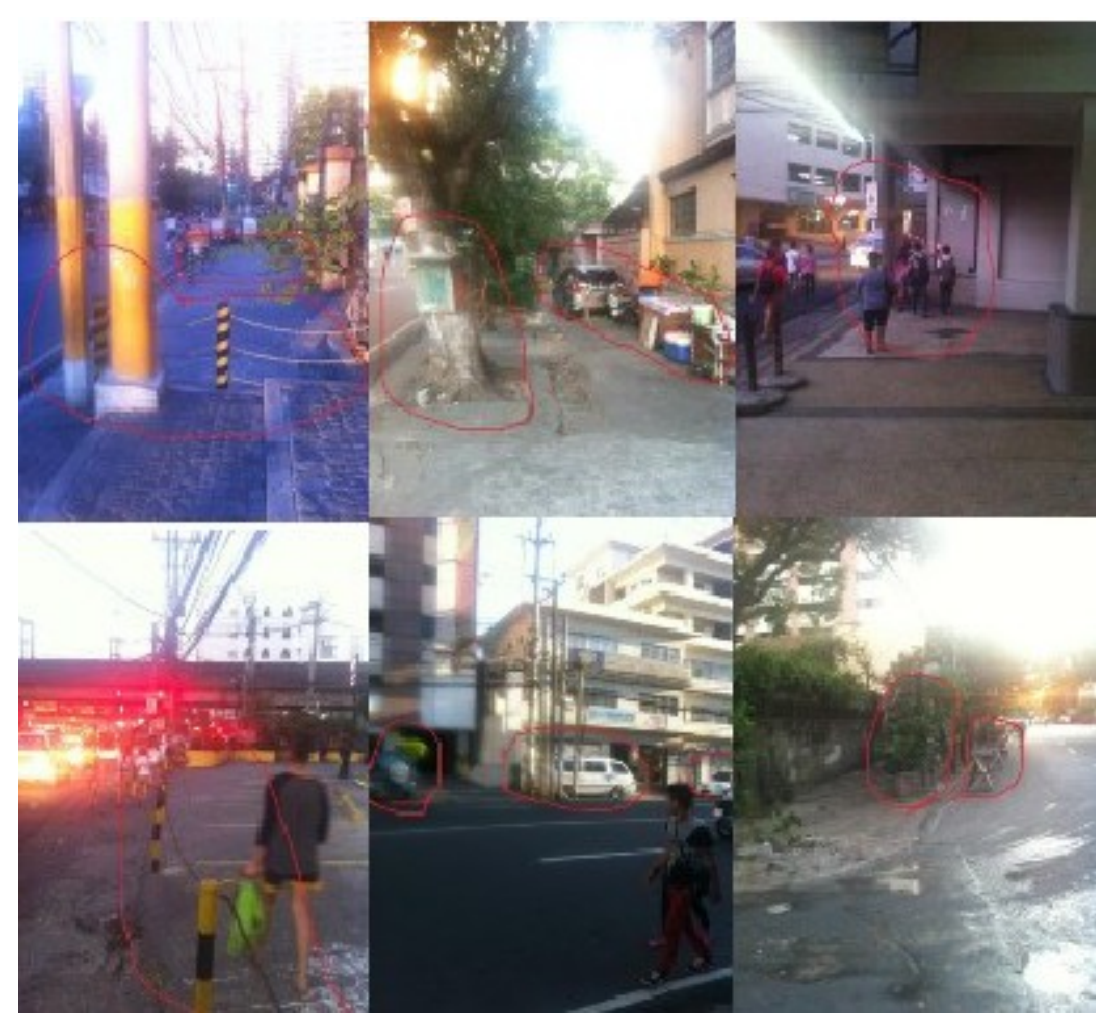

Figure 4

\subsection{Results of Observations}

In this case study, the data and information were collected from the observation, maps and taking pictures of selected area in Metro, Manila. Pictures and maps were previously analyzed and utilized to aid the case study in understanding the gathered results. These results will then be used to answer the the problems of urban mobility for that area to make a decisive conclusion for design of the sustainable transportation. Finally, propsal sustainable transportation specifics to those who might be concerned with and interested in the topic will be suggested. Specifically, analysis was made to find an efficient methods and standards to solve problems and challenges of urban mobility as well. According to the pictures and observation of selected zone in Metro Manila, this data and information were realize as the problems and challenges of urban mobility for that area, as following:

I. Lack of proper sidewalk: It was realized that the most imprtant problem of urban mobility in this area is sidewalk, as shown in figures, there is no proper facility for walker to move on the streers because of many barriers through walkside like electric posts, trees, cars, different and other objects;

II. Lack of municipality effort to widen roads: There is possible to widen roads and sidewalk by municipality as an effecient solution to improve the movement of the walkers and cars safely, and designing a good sustainable transportation by possessing enough space (land). municipality can negotiate with owners of lands and organizations to give some privileges to them for giving few meters of their lands to public area. 
III. Lack of proper policies for traffic: There is no proper control and policies about parking the cars, and putting objects in the public areas and sidewalk by traffic police: In fact, most parts of sidewalk are useless, even some buldings use sidewalk as the park area that it can be very dangerous for walker because there is no facility to walk through sidewalk. So, whether walkers want or not, they just can move through the street that it can be made accident and traffic jam on the street.

IV. Lack of Bikeway: As shown in Figures: There is no any bilkway for those who are interested to ride the bike instead of the car and taxi to decrease the expenses and pollution, there is just improper bikeway in one side of Quirino Ave. (Figure E1), that it needs to fix and remove many barriers through that. Without bikway for these areas, people can not be motivated to use the bike because it is very dangerouse and hard to ride among cars. Bikway is an important way to reduce traffic jam, accident, and pollution;

$V$. Lack of exclusive or proper Bus line: As shown in Figures, there is no any exclusive or proper roads for buses as public transit (BRT). So, the buses have to move among others cars, and it makes many problems for other cars and taxis to move easily and fastly because of stopping and uploading or loading passangers. Public transit is also a good solution for reducing the problem traffic jam and using private car, and;

VI. The buildings under construction: Also, the areas that are under construction can make many problems for urban mobility as well. Because putting materials and equipment through sidewalk and sometimes closing sidewalk as a security reason for walkers, but if there is no any space for walkers to move through sidewalk, so they have to move on the street and increasing the percentage of accident for them. So, certain organizations and municipality always should inspect the walkside of construction areas.

Finally, it was emerged that lack and improper walkside, bickways, public transit as most problems for people of that zone respectively, especially, on the streets, because being cars, electric posts, trees, and pedicabs. Also, lack of strategy to interoduce and apply green transprtation as an efficient method to reduce expences, pollution, accident and etc. and it can give good influence to lifestyle of people the area of study as well.

\section{Proposal Design \& Solutions for Sustainable Transportation}

As Lewis Mumford (The Roaring Traffic's Boom) said "adding highway lanes to deal with traffic congestion is like loosening your belt to cure obesity". So, adding road is not a good way to solve problems of transportation. Transit Oriented Development applied sustainable desig that refers to an approach to urban design where policies promote urban development of higher density along mass transit corridors. The rationale for this approach is that significant energy efficiency and transport efficiency can be realised through urban designs where mass transit provides rapid access to the main nodes of urban activity.

This case study also notes that most trips involve a combination of several modes of transport. Thus, modal integration is stressed as a major component of any urban mobility strategy. For example, the construction of a high-capacity public transport system needs to be integrated with other forms of public transport, as well as with other modes. 
Such integration with various 'feeder services' is crucial to ensure that metros, light rail and bus rapid transit (BRT) systems can fully utilize their potential as a 'high-capacity' public transport modes. It is therefore essential that planners take into account how users (or goods) travel the 'last (or first) mile' of any trip. By way of an example, it is not much use to live 'within walking distance' of a metro (or BRT) station, if this implies crossing a busy eight-lane highway without a pedestrian crossing, or if one is unable to walk to the station (due to disability, or lack of personal security). Likewise, it is unlikely that urban residents will make use of metros (and BRTs), if the nearest station is located beyond walking distance, and there is no public transport 'feeder' services providing access to these stations or no secure parking options for private vehicles near the stations.

\subsection{The Main factors for Sustainable Desig (Avoid, Shift, Improve)}

Avoid: This first strategy seeks to avoid unnecessary travel and reduce trip distances. It implies measures where land use and transport planning are properly integrated and mixed use development is promoted, and where there is a greater role of information and communications technologies (ICT) to reduce the number of trips being taken by a person. This measure can effectively increase accessibility and reduce trip distances and times by properly integrating land use and transport and by developing areas so that home, work and shopping locations are near each other (mixed use development). This is accomplished through urban development master plans. Additionally, this approach can avoid many trips due to the ease with which ICT can replace many activities that previously required travel. The "Avoid" strategy is described first since, if its policies are applied in a comprehensive way, it can have a great impact on urban transport and provide great social, economic and environmental benefits.

Shift: This strategy seeks to shift passengers towards more sustainable transport modes. It means that citizens who are using automobiles or motorcycles should be encouraged to start using more public and non-motorized transport. It uses all travel demand management measures in its toolbox, as well as a better development of inter-city passenger and goods transport.

It also seeks to persuade existing public and nonmotorized transport users to continue using them, applauding their contribution to sustainability. The shift approach can be the second most potent means of delivering sustainable urban transport if implemented properly. If one can implement Avoid and Shift strategies in one city, most of the hard work has been done, though more can be still improved.

Improve: The third strategy focuses on policies that aim to improve transport practices and technologies. It is a more technological approach to improving urban transport problems. Its measures include improving fuel quality and vehicle fuel efficiency standards, developing vehicle emission standards, implementing vehicle inspection and maintenance (I\&M) policies, and transitioning to "intelligent transportation systems" that take advantage of information and communication technologies to improve transport management. It also emphasizes the need to improve freight transport technologies and logistics.

Though this measure is not generally seen as the most crucial to achieve substantial benefits in the short and long term for urban transport, it is an important complement to the Avoid and Shift measures, and can achieve incremental benefits for society, the environment and the economy. 


\subsection{Standards of Sustainable Urban Mobility Design}

\section{A. User Priorities}

To encourage more sustainable travel patterns and safer streets, designers should place pedestrians at the top of the user hierarchy (see Figure 5).

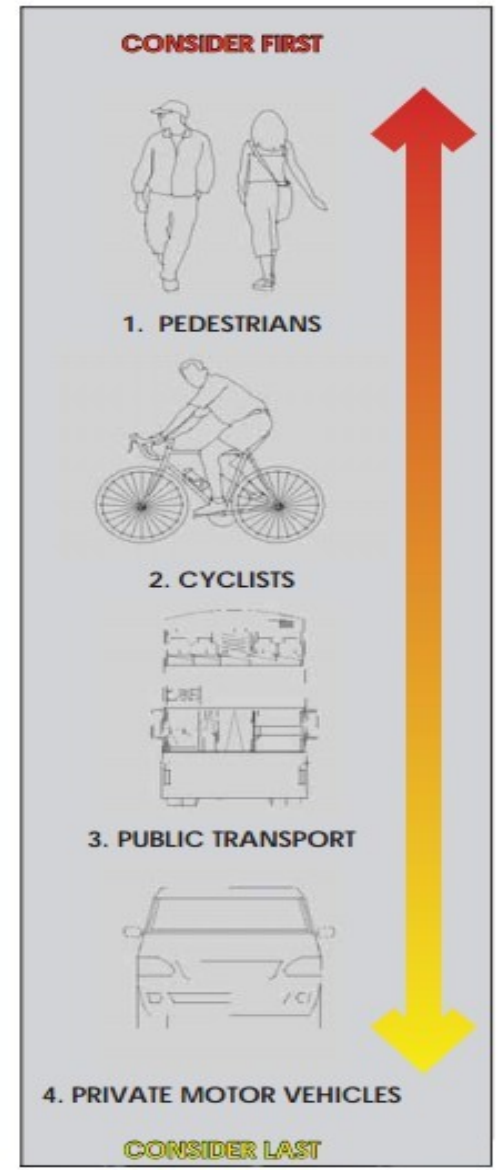

Figure 5. Consideration issues for sustainable transportation

\section{B. The Balanced Approach (Key Design Principles)}

To guide a more place-based/integrated approach to road and street design, designers must have regard to the four core principles presented below:

\section{Design Principle 1:}

To support the creation of integrated street networks which promote higher levels of permeability and legibility for all users, and in particular more sustainable forms of transport. As shown in figure 6;

\section{Design Principle 2:}

The promotion of multi-functional, place-based streets that balance the needs of all users within a self-regulating environment. As shown in figure 7;

\section{Design Principle 3:}

The quality of the street is measured by the quality of the pedestrian environment. As shown in figure 8 , and; 


\section{Design Principle 4:}

Greater communication and co-operation between design professionals through the promotion of a plan-led, multidisciplinary approach to design. As shown in figure 9.

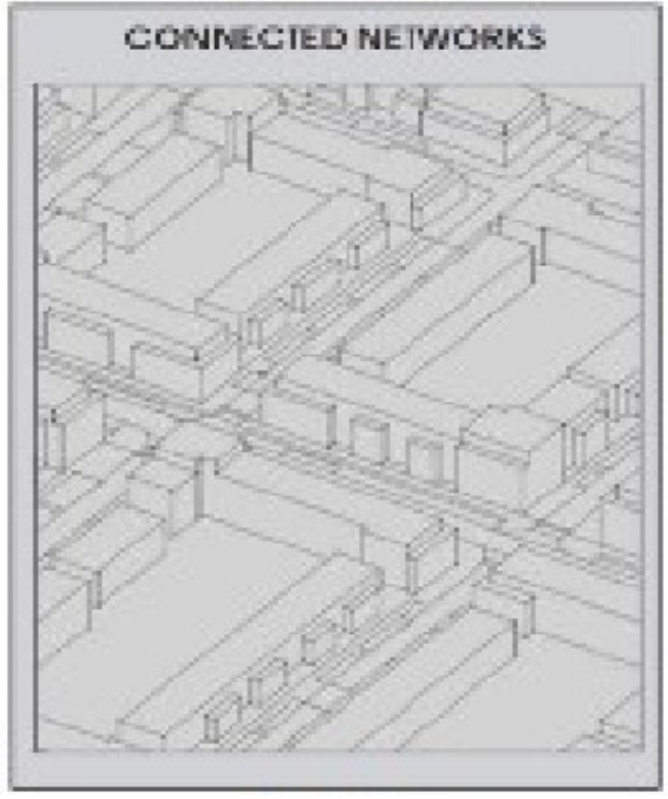

Figure 6

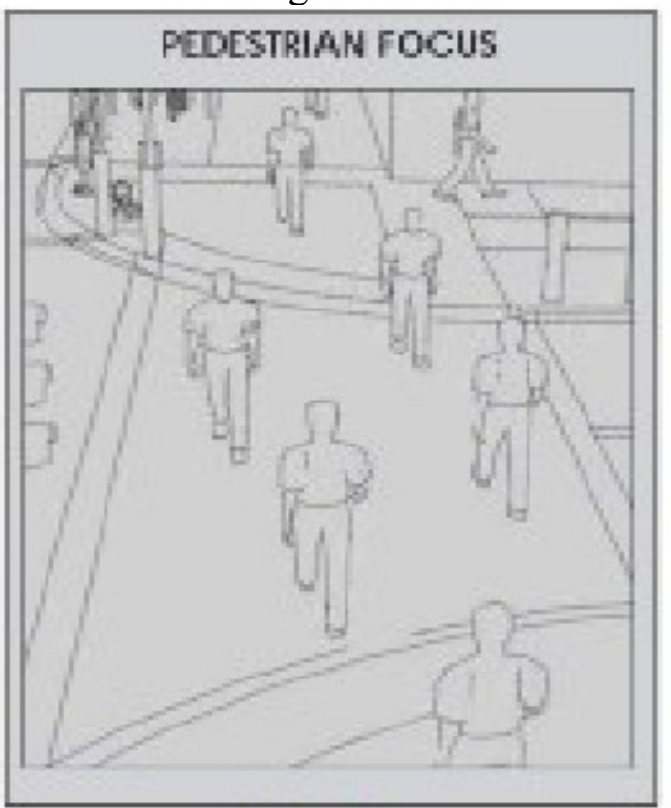

Figure 8

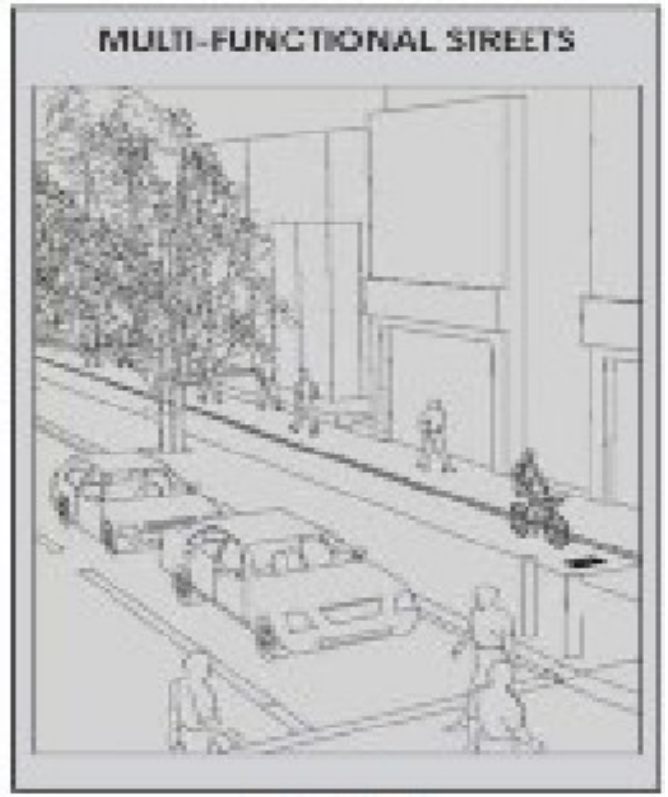

Figure 7

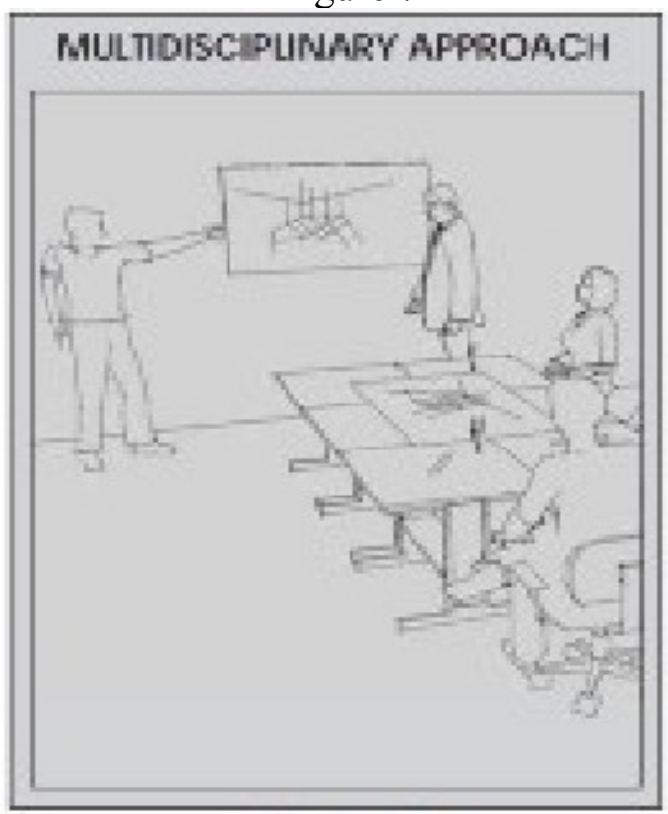

Figure 9

\section{Pedestrian and Cyclist Environment}

A. Footways: Minimum footway widths are based on the space needed for two wheelchairs to pass each other $(1.8 \mathrm{~m})$. In densely populated areas and along busier streets, additional width must be provided to allow people to pass each other in larger groups. In this regard:

I. The width of footways should increase from Suburbs (lower activity), to

Neighbourhood (moderate activity) and to Centres (higher activity) and as 
12

development densities increase;

II. The width of footways should increase according to function from Local (lower activity), Link (moderate activity), to Arterial streets (moderate to higher activity) as connectivity levels increase, and;

III. The footway should be maintained at a consistent width between junctions and should not be narrowed to accommodate turning vehicles.

Figure 4.34 illustrates the space needed for pedestrians to comfortably pass each other with reference to the anticipated levels of activity within a street.

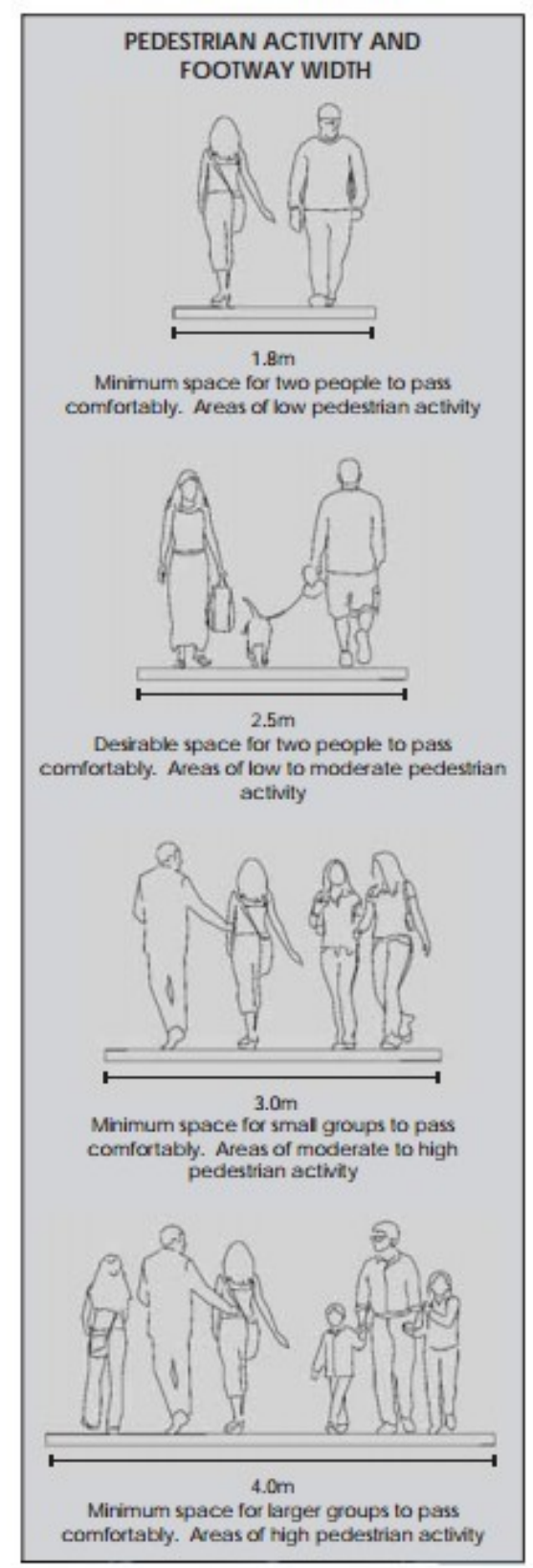

Figure 10: Diagram showing the amount of space needed for pedestrians to pass each other with regard to pedestrian activity levels 


\section{B. Cycle Facilities}

This Manual and the National Cycle Manual (NCM) promotes cycling as a sustainable form of transport and seek to rebalance design priorities to promote a safer and more comfortable environment for cyclists. To achieve these goals, the NCM recognises the importance of slowing vehicular traffi $\mathrm{c}$ within cites, towns and villages, and advocates many of the measures contained within this Manual, such as narrower vehicular carriageways and tighter corner radii. The principle source for guidance on the design of cycle facilities is the NCM published by the National Transport Authority. The NCM provides designers with a comprehensive set of design measures aimed at achieving an overall quality of service that is appropriate to user needs.

Figure 11, from the NCM, provides an overview of the integration and segregation of cycle traffi c within the carriageway based on vehicle speeds and traffic volumes. Designers must also have regard to the measures contained within this Manual when applying the NCM. For example: To minimise the width of vehicular carriageways from kerb to kerb, preference should be given to the implementation of Raised Cycle Lanes or Raised Cycle Tracks over those design solutions where cyclists and vehicles are at grade, and Cycle facilities on most streets within Centres, Neighbourhoods and Suburbs will need to be integrated with on-street parking. Figure 12 illustrate this with regard to a Cycle Track.

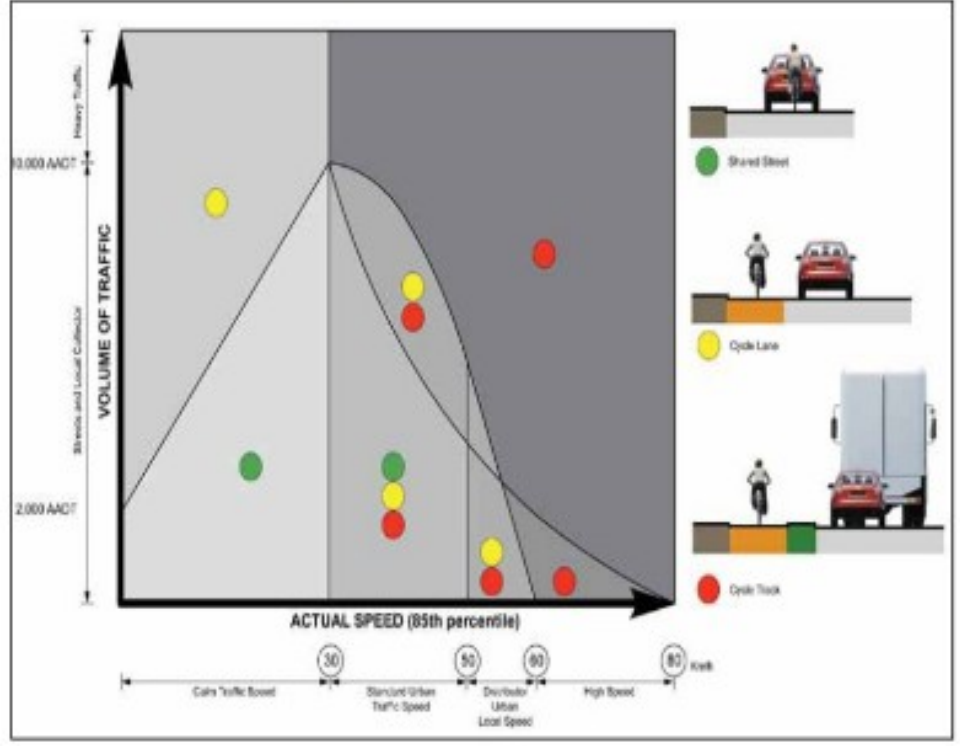

Figure 11.

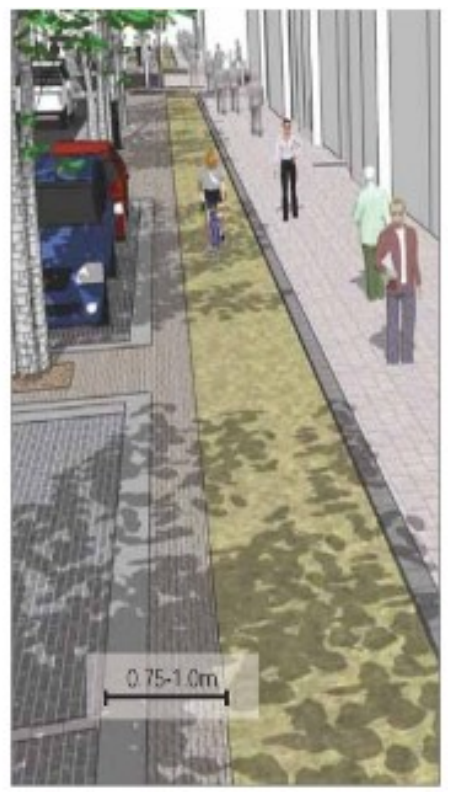

Figure 12.

\section{Carriageway Widths}

According to UK Manual for Streets [4], the narrow carriageways are one of the most effective design measures that calm traffic. The width of the vehicular carriageway is measured from kerb to kerb or from the outside line of a Cycle Lane or from the edges of parking spaces (where the latter facilities are provided). Designers should minimise the width of the carriageway by incorporating only as many lanes as needed to cater for projected vehicle flows and by reducing the size of individual lanes to meet predominant user needs (see Figure 13). 


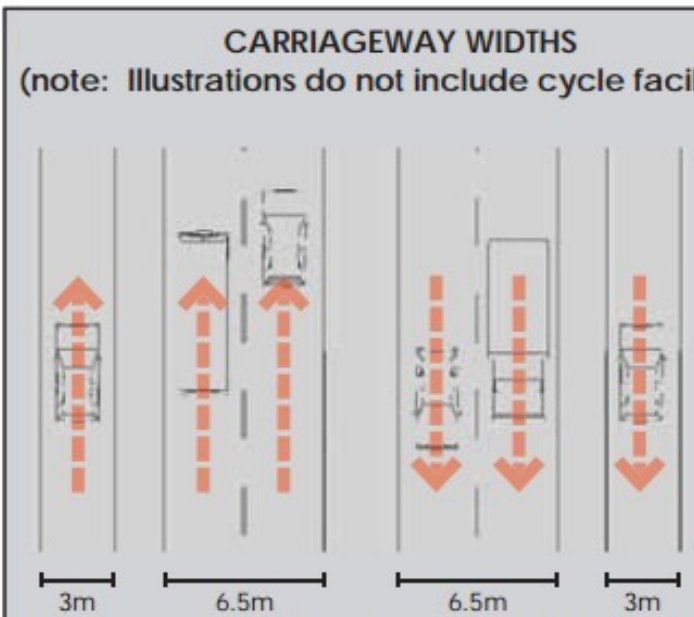

Carriageway widths for heavily-trafficked Arterial and Link streets in boulevard configuration. Main carriageway suitable for moderate design speeds. Includes access lanes with a lower design speed.

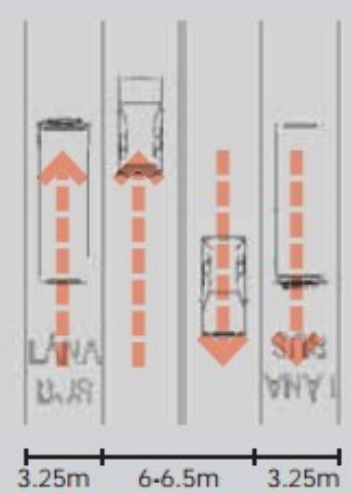

Standard lane/carriageway widths for multi lane Arterial and Link streets, including bus lanes. Range for low to moderate design speeds.

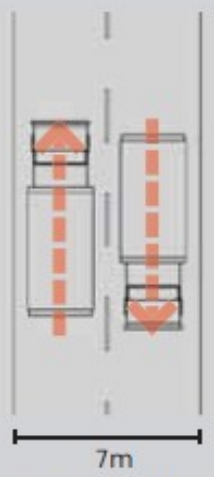

Carriageway width for Arterial and Link streets frequently used by larger vehicles.

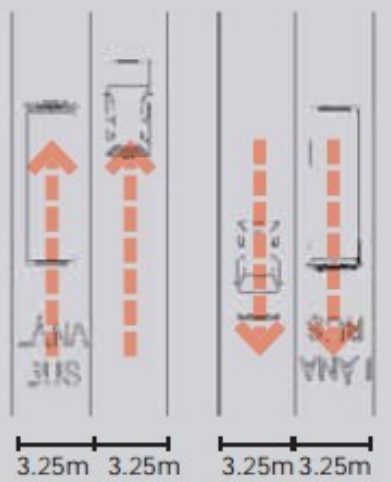

Standard lanes widths for multi lane carriageway for Arterial and Link streets in boulevard configuration, including bus lanes.

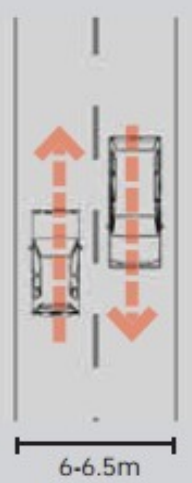

Standard carriageway widths for Arterial and Link streets.

Range for low to moderate design speeds.

Standard carriageway width for Loca/streets
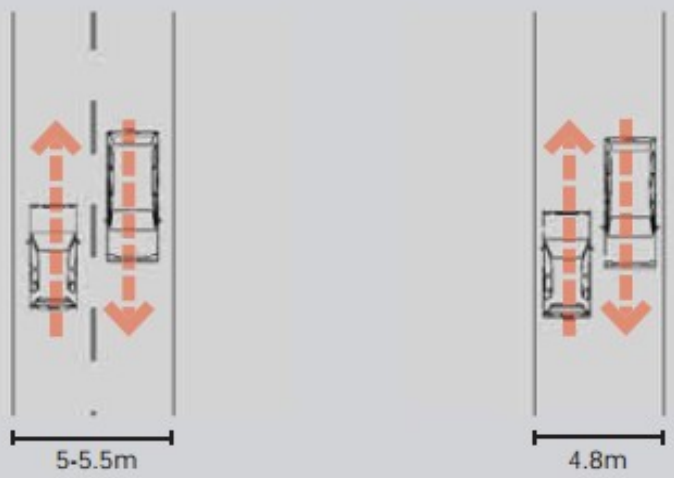

Carriageway width for Local streets with a shared surface carriageway.

Figure 13: Carriageway Widths 


\subsection{Proposed Design of case study}

A. Proposed Design for Taft Ave.

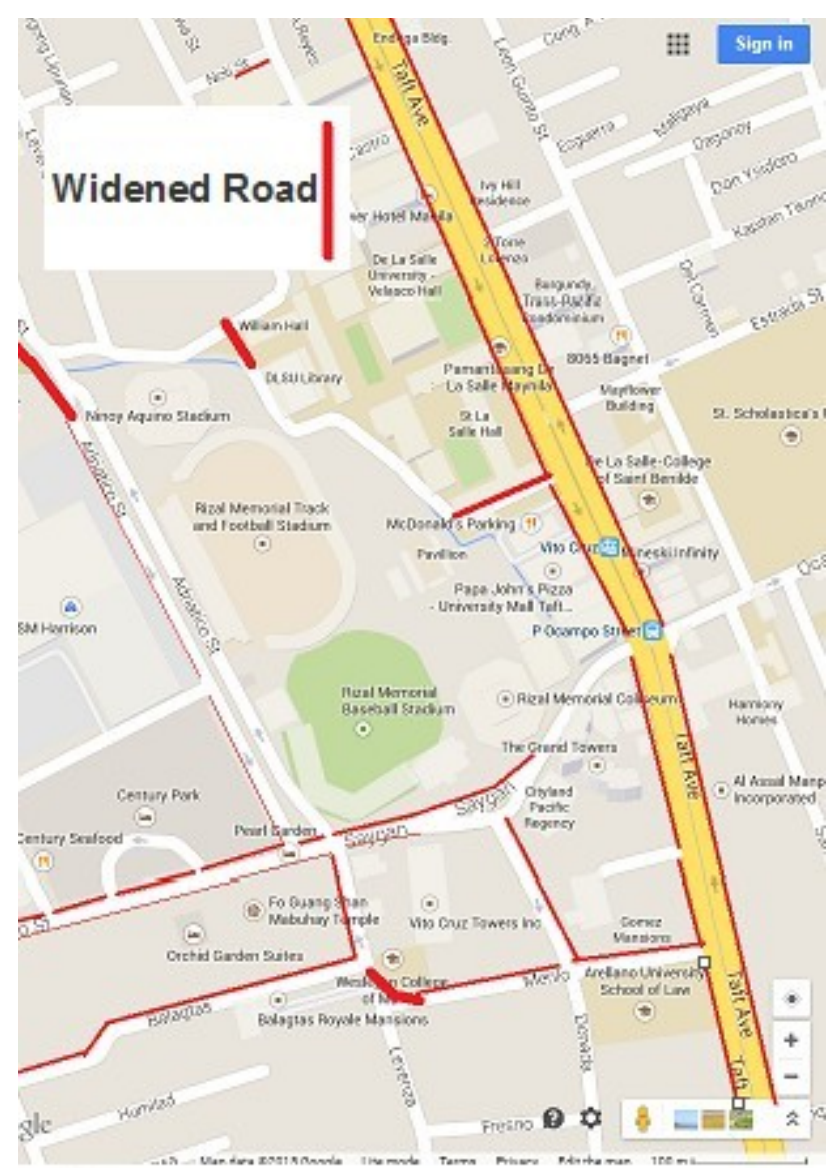

Profile of Taft Ave.

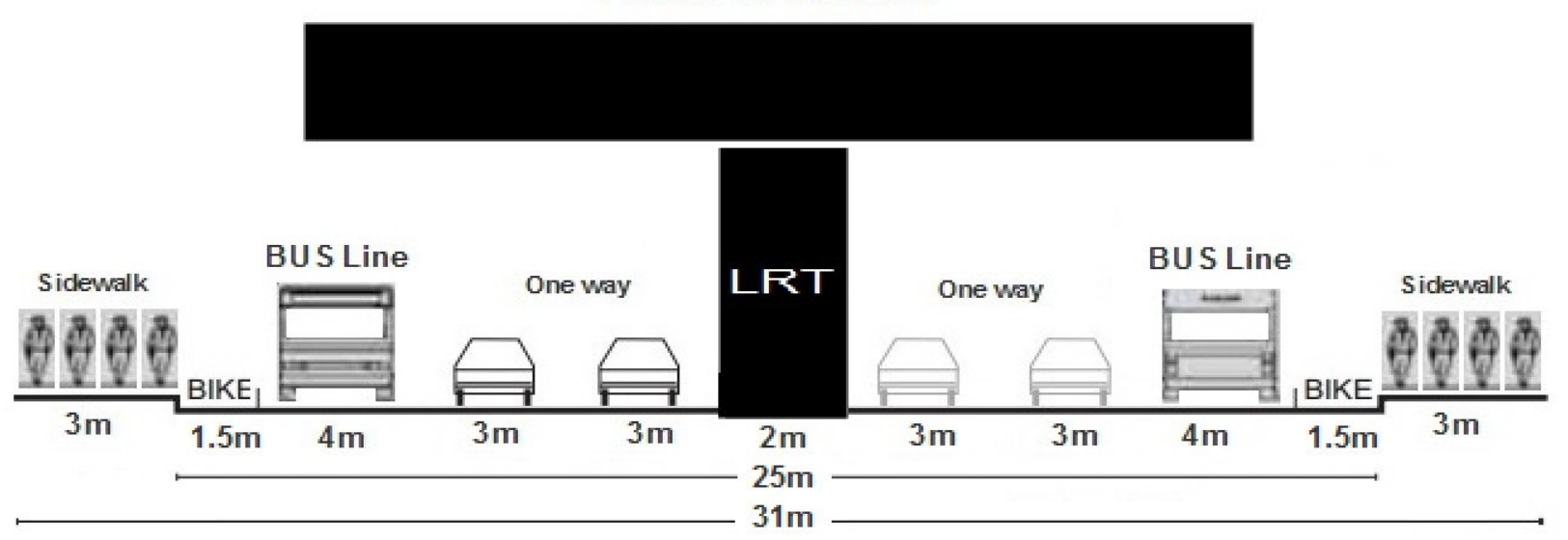

Figure 14. Proposed Design for Taft Ave 
B. Proposed Design for Vito Cruz St.

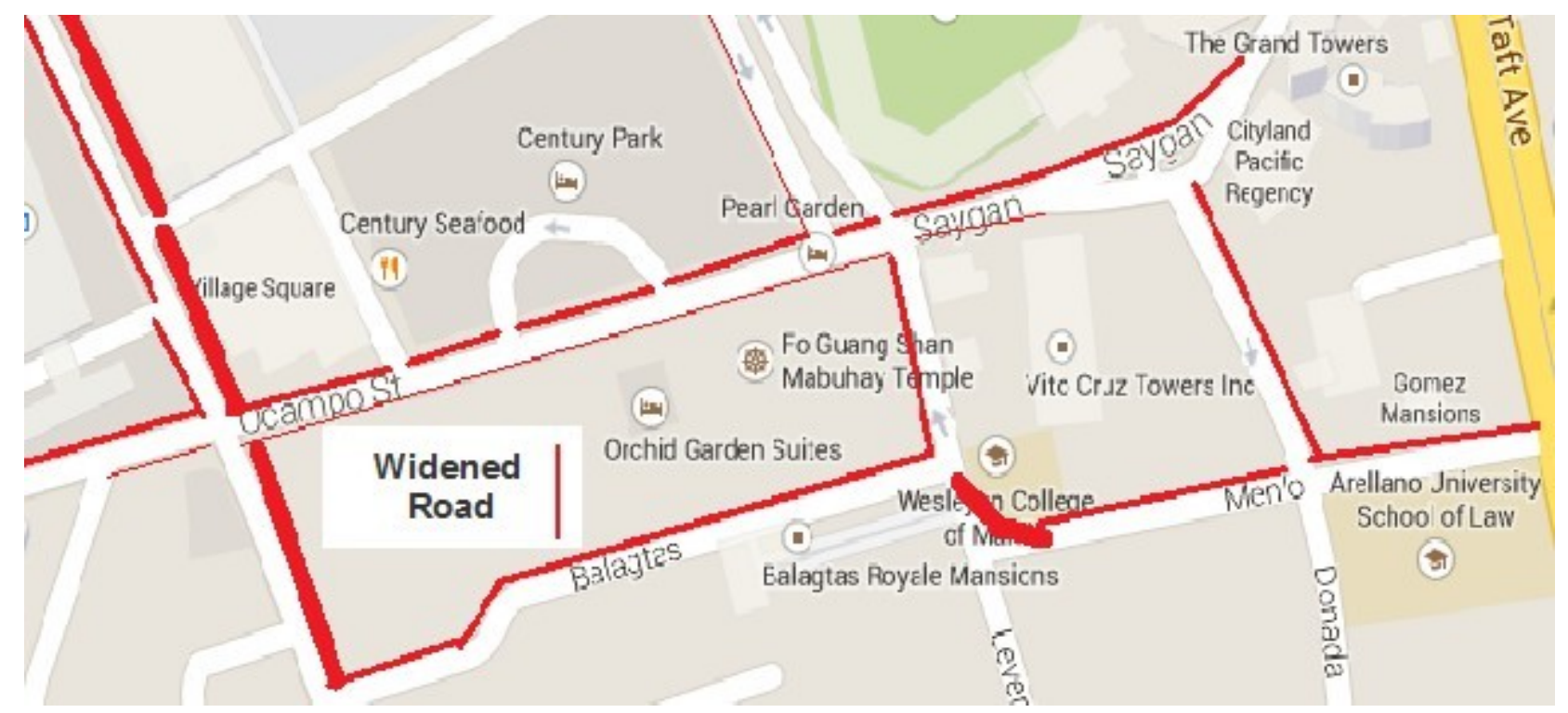

Profile of Ocampo \& Saygon St. (Vito Cruz St.)

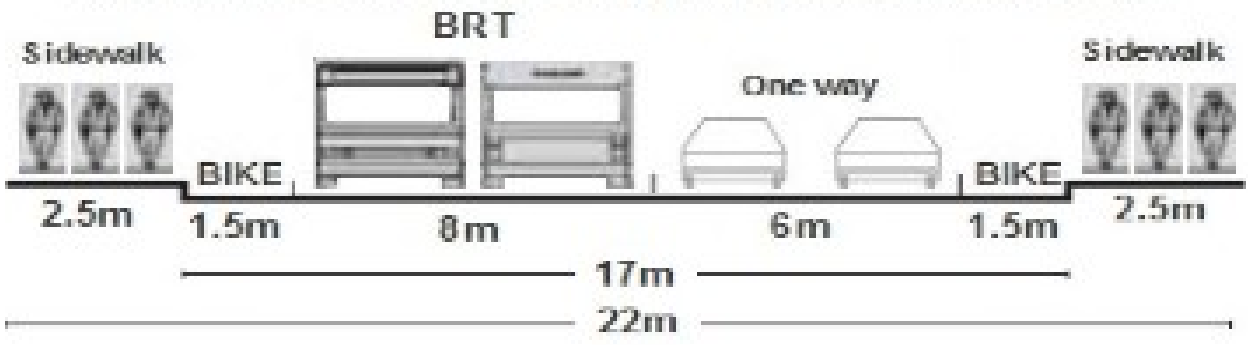

Profile of Menlo \& Balagtas (from Taft Ave. to Mabinl St.)

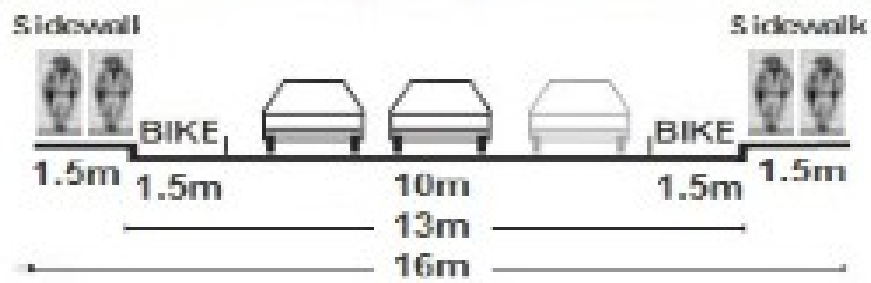

Figure 15. Proposed Design for Vito Cruz St. 
C. Proposed Design for Mabini St. \& Adriatico St.

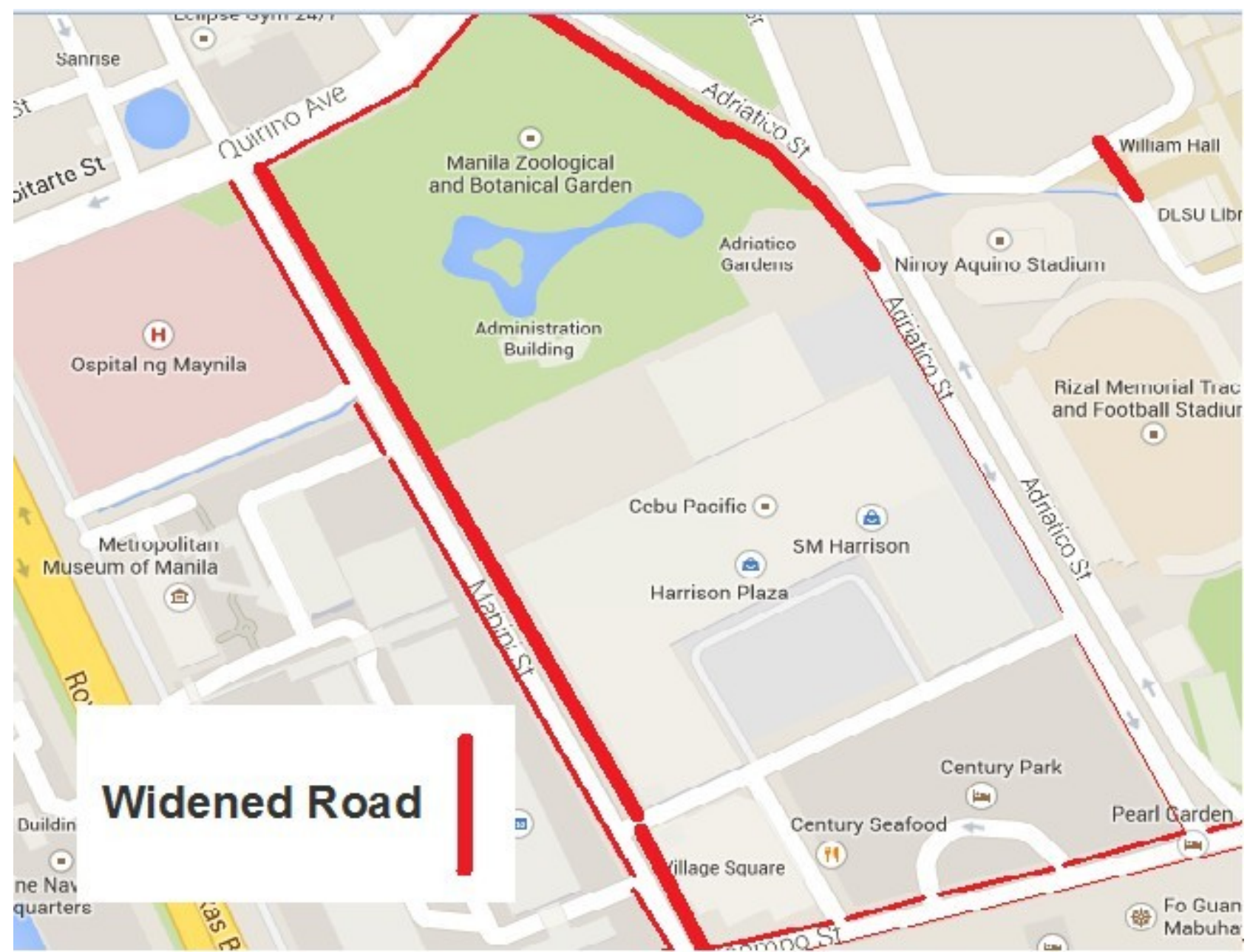

Profile of Mabini St.

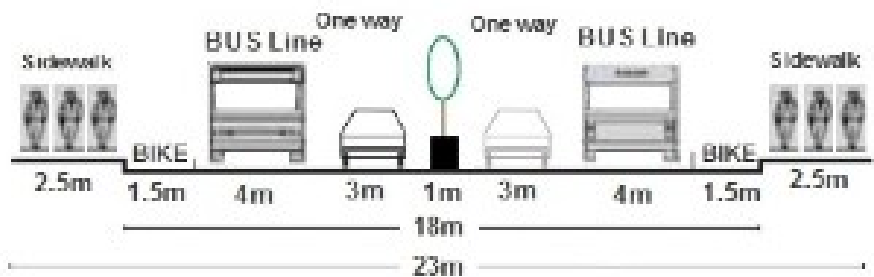

Profile of Adriatico St. (from Vito Cruz to Mabini St.)

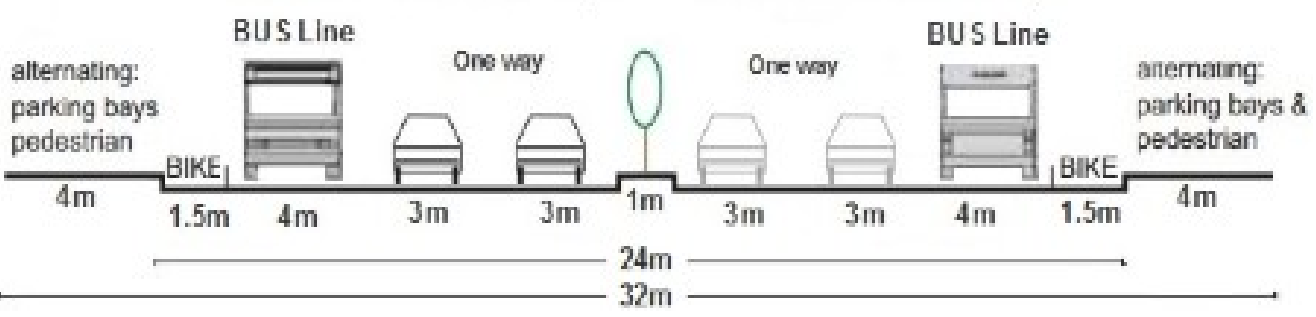

Figure 16. Proposed Design for Mabini St. \& Adriatico St. 
D. Proposed Design for Quirino Ave.

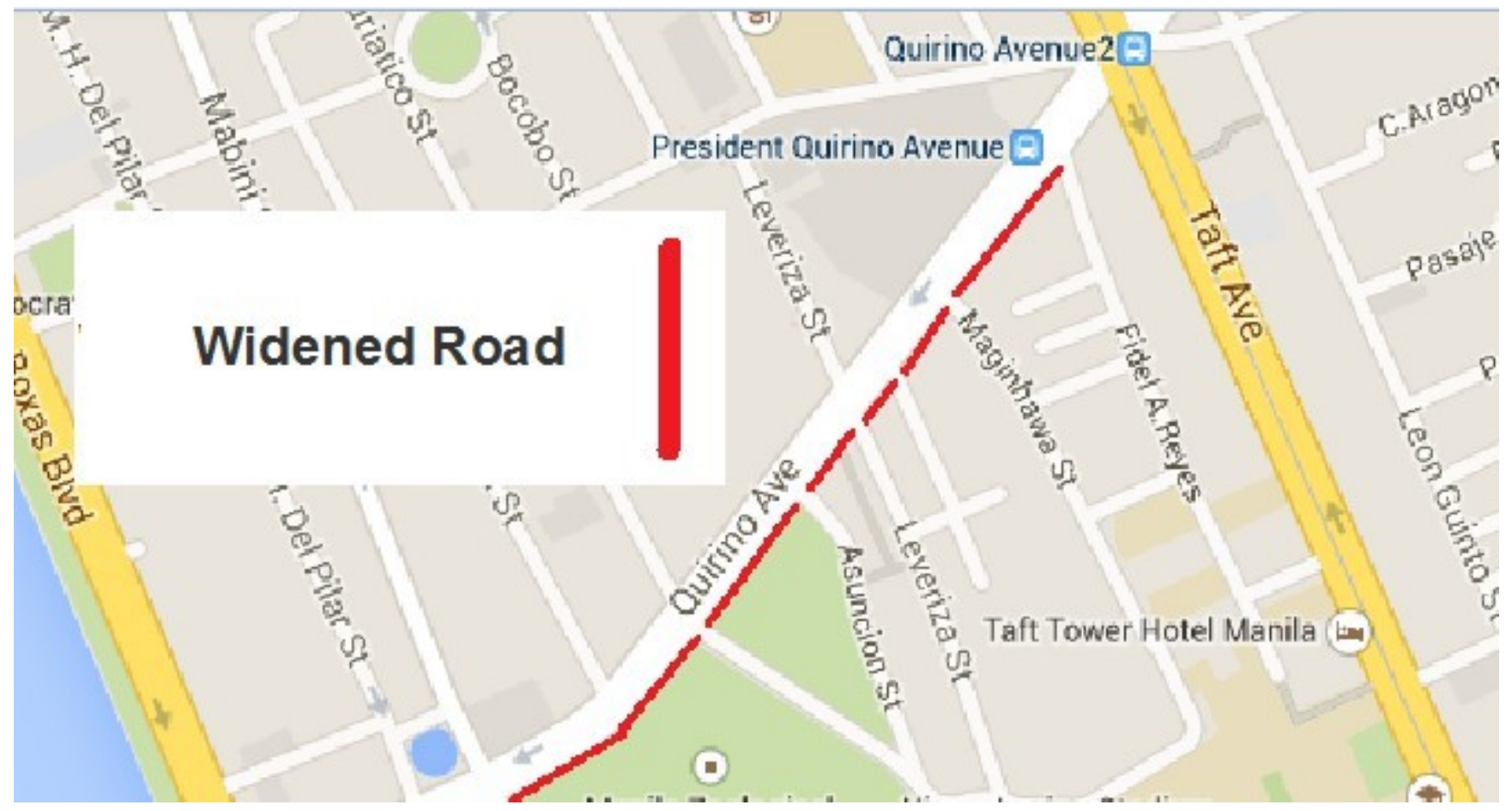

Profile of Quirino Ave.

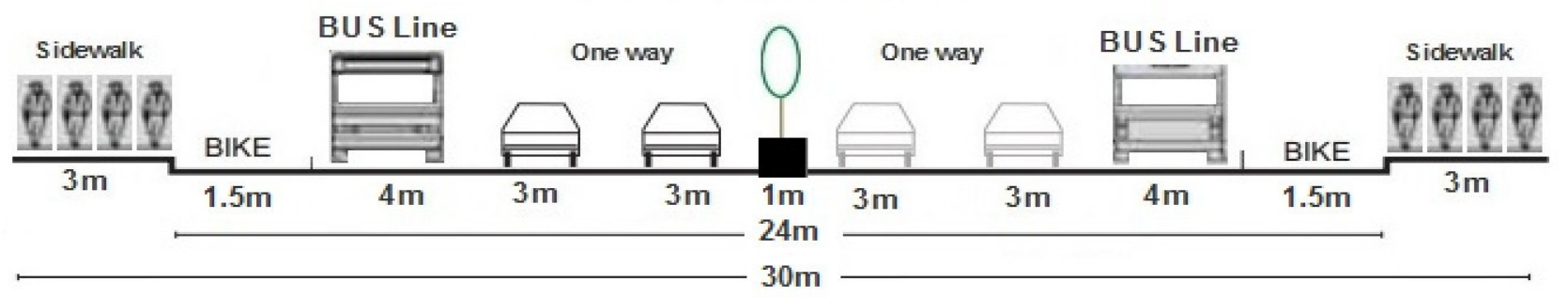

Figure 17. Proposed Design for Quirino Ave. 


\subsection{Overview of widened space for public area, Bike Station, and Bus Station}

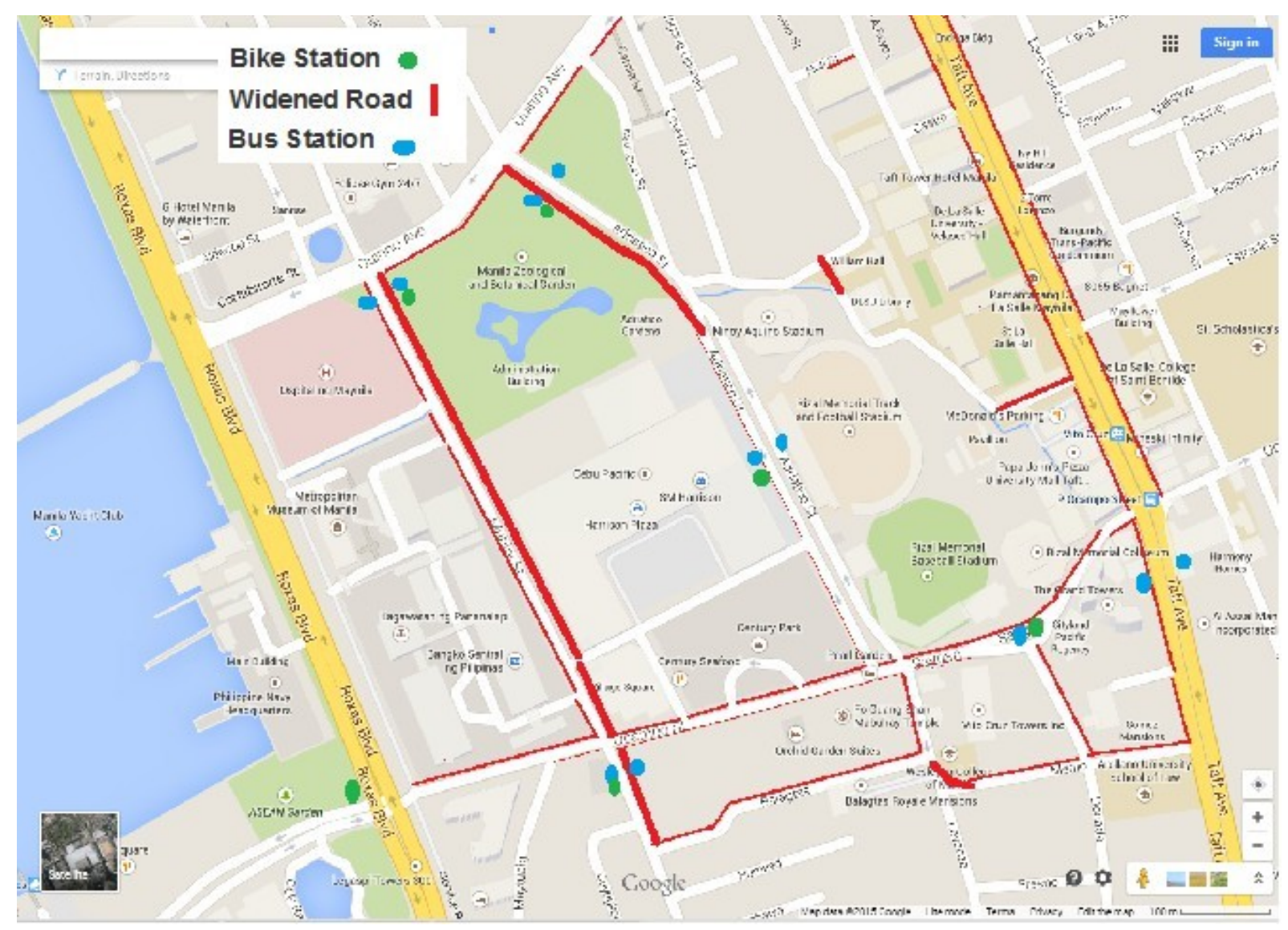

Figure 18. Overview of the proposed sustainable transportation and urban mobility for the scope of this study

\section{Conclusion}

It was observed that transportation and mobility are central to sustainable development. Sustainable transportation can enhance economic growth and improve accessibility. Sustainable transport achieves better integration of the economy while respecting the environment. I recognize the importance of the efficient movement of people and goods, and access to environmentally sound, safe and affordable transportation as a means to improve social equity, health, resilience of cities, urban linkages and productivity of this area. In this regard, I take into account road safety as part of our efforts to achieve sustainable development. It should be supported the development of sustainable transport systems, including energy efficient multi-modal transport systems, notably public mass transportation systems, clean fuels and vehicles, as well as improved transportation systems in rural areas. I recognize the need to promote an integrated approach to policymaking at the national, regional and local levels for transport services and systems to promote sustainable development. I also recognize that the special development needs of landlocked and transit developing countries need to be taken into account while establishing sustainable transit transport systems. I acknowledge the need for international support to developing countries in this regard. 


\section{Recommendations for Sustainable Transportation}

This case study objective is to make a substantial contribution to the uptake of innovative and green urban mobility solutions by facilitating dialogue and exchange, promoting successful policy, providing guidance and tailored advice to city officials, and fostering future cooperation on research, development and innovation. Practically, there are three different kind of solutions together that can help to exchange transit system to sustainable urban mobility for that zone that are as:

I. Policy solutions: The public administration and municipality have big role to regolate some proper laws that can help to apply sustainable urban mobility in the cities of the Philippines. For example: municipality must inform and control people that they must never occupy sidewalk, public areas, and roads with objects, cars, pedicabs strictly. The owner of building and people do not have to make barrier through walkside and roads for park of their cars. If people did not follow rules and they broke traffic regulations then municipality or traffic officer must charge them accurately. The challenges of policy-making in the transport sector are complex and multidimensional. Transport-related activities affect economic growth, social development and the environment in many diverse ways. They pose particular problems in the context of urbanization and a separate set of challenges in rural and remote areas, including in mountainous areas. Land, maritime and aviation transport present different issues for resolution but also need to be considered. The social dimensions of transport include affordability and the impact on, inter alia, community health and safety of transport services, infrastructure, gender and age aspects, employment and labour conditions and providing for those with special needs. A further challenge facing policy makers is the wide variety of stakeholders whose input is relevant in formulating policies and whose assistance is often essential in implementing them effectively. Within and between Governments, coordination and consultation are essential in moving towards sustainable development. Dialogue with major groups is encouraged.

II. Technical solutions: There are many facets to the impact on the environment of transport-related activities and infrastructure. Accidents, noise and air pollution are adverse impacts associated with the transport sector. Emissions from vehicles and other modes of transport are harmful to human health and the environment. The demand for transport services is significant and likely to rise. Transport systems affect human settlements in various ways, including urban conditions and land use. There are many methods and ways to solve problems of urban mobility towards exchanging to sustainable transportation by applying efficient techniquesd and

activities. Normally, these activities must be organized by public sectors and municipality that they are briefly around six themes:

- Public transport;

- Transport infrastructure, especially for walking and cycling;

- City logistics;

- Integrated planning / sustainable urban mobility plans;

- Network and mobility management, and;

- Clean vehicles (walking and cycling). 
III. Social solutions: The metaphor and language of sustainability has become the central manner of expressing ecological concerns about the economy and technology today. Ecologists have long argued that world population needs to be limited. Another area of political ambivalence of ecological policy is in the area of population limitation. So, public sectors and government should lead sustainable plan in urban mobility and besid that they must control the Philippine's population. Urban mobility challenges can not only be solved without control of rate of the population. The government should inform people to reduce population rate for improving their lifestyles, education, sharing city facilities, and etc. the population limitation can help to efficiently implement sustainable transportation and mobility in every city all over the world. Decisions concerning transport issues should reflect the fact that economic development, social development and environmental protection are interdependent and mutually reinforcing components of sustainable development. To contribute to sustainable development, transport should, inter alia, be affordable, safe and ensure mobility, should provide access to all sectors of society on an equitable basis, and should be efficient and environmentally sound.

\section{REFERENCES}

[1] Blak W.R. (1996). "Sustainable transportation: a US perspective," Journal of transport geography, 4(3), 151-159.

[2] Black, J. A., Paez, A., \& Suthanaya, P. A. (2002). Sustainable urban transportation: performance indicators and some analytical approaches. Journal of urban planning and development, 128(4), 184-209.

[3] Banister, D. (2008). "The Sustainable Mobility Paradigm," Transport policy, 15(2), 73-80.

[4] Buis, J. (2009) A new Paradigm for Urban Transport Planning: Cycling Inclusive Planning at the Pre-event Training Workshop on Non-Motorized Transport in Urban Areas, $4^{\text {th }}$ Regional EST Forum in Asia, 23 February 2009, Seoul, Republic of Korea.

[5] Haghshenas, H., \& Vaziri, M. (2012). Urban sustainable transportation indicators for global comparison. Ecological Indicators, 15(1), 115-121.

[6] Litman, T. (2003). "Sustainable Transportation Indicators," Victoria Transport Policy Institute, 100.

[7] Litman, T., \& Burwell, D. (2006). "Issues in Sustainable Transportation," International Journal of Global Environmental Issues, 6(4), 331-347.

[8] NTA (2011). National Cycle Manual. National Transport Agency.

[9] Relogle MA (1991). "Sustainable transportation strategies for third-world development," (No. 1294).

[10] oung, A., \& Barrie, E. (2010). Manual for Streets 2; Wider Application of the Principles. In European Transport Conference, 2010. 